\title{
Health Care System Financing And Design: Convergent Trends In North America And Europe
}

Adora Holstein, Robert Morris University, USA

Patrick Litzinger, Robert Morris University, USA

\begin{abstract}
A study of the evolution of health care systems in Canada and Europe shows that the earlier effort at making health care services available to everybody was followed by reform measures focused on cost containment. In the U.S., the rapid rise in health care cost and low access are widely recognized as twin problems. Health care reform in this country first focused on cost containment through managed care to make health insurance affordable, and then shifted to expanding access to coverage at the state level without doing away with the private health insurance market.
\end{abstract}

Keywords: National health care systems; health care financing; universal coverage; health care statistics; cost containment; managed care, health care plans, Medicaid; Medicare

\section{INTRODUCTION}

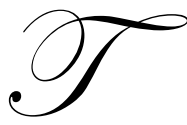

he United States remains the only high-income member of the Organization for Economic Cooperation and Development (OECD) that does not have universal health care coverage. The health care system is predominantly private in both financing and delivery. Most health care services are delivered by private providers, and over half are funded by private insurance and/or paid for by the patient out-ofpocket. Public programs such as Medicare for the elderly and disabled, Medicaid for non-elderly, low-income individuals and their dependents, and the State Children's Health Insurance Program (SCHIP) for low-income children serve as multiple payers for benefit packages purchased from private health insurers (Gruber 2008). Both Medicaid and SCHIP are funded by state revenues with federal matching grants, while Medicare is financed through a trust fund funded by payroll taxes. The absence of mandatory purchase of health insurance has led to adverse selection characteristic of voluntary insurance markets. The ability of insurance to pool financial risk and promote access to services is weakened because those with greater health risks are more likely to take out insurance and to insure at higher levels, as compared with those in good health. Profit-motivated, private health insurers are likely to raise health care premiums to keep up with rising reimbursements. Self-interest based on rational cost-benefit analysis causes healthier individuals to opt out of health insurance, thus increasing the risk among the pool of insured. This leads to a never-ending cycle of increasing reimbursement, premium, and risk pool that can eventually lower coverage to those who are insured, or worse, limit access to affordable insurance for higher-risk individuals.

According to OECD Health Data (2006), the U.S. has the highest per capita health care expenditure $(\$ 5,711)$ - more than twice the OECD average of $\$ 2,818$. It also shows the U.S. share of health care in GDP $(15.3 \%)$ as the highest, with the OECD average only at 9\%. Data compiled for Academy Health (2007) by University of Minnesota's School of Public Health show that between 2001 and 2006, the increase in health insurance premiums (78\%) exceeded wage growth (19\%), and overall inflation (17\%). The rising cost of health insurance has led initially to an increase in lower-cost benefit plans that cover fewer services and/or have higher patient cost share, and recently to a decline in employer sponsored-health coverage. As a result, the number of uninsured has risen to 47 million or $16 \%$ of the population as of 2007(Academy Health 2008). 
Several economic principles explain why the cost of health care may rise faster than other goods and services. The availability of third-party insurance poses a moral hazard of overconsumption on the part of some patients. Further increasing demand is information asymmetry between patient and physicians, along with the risk of malpractice lawsuits, which can lead to unnecessary services being prescribed. Among the uninsured, demand elasticity suggests that the price increase brought about by excess demand can reduce consumption of preventive care and health services for non-life threatening illnesses. Reduced utilization by those who cannot afford to buy insurance on their own could mean higher health care costs for the country in the long-run.

Canada, the United Kingdom, and other high-income OECD members in Europe provide universal coverage. Their systems rely heavily on public financing through a combination of a social security trust fund and general tax revenues. In Canada, Japan, Germany, and France health care delivery by private health care agencies is combined with public financing (Cutler 2002). In the so-called public integrated system of the U.K., Norway, Sweden, Finland, Greece, Portugal, Spain and New Zealand, insurance and service delivery are handled by a single public agency (Docteur and Oxley 2003). During the 1960s and 1970s, many countries with universal coverage found that health-care spending grew at rates that most governments considered unsustainable with public finances. With various cost containment measures, spending growth has slowed considerably over the past two decades, but continues to grow at rates exceeding overall economic growth in many OECD countries. According to OECD Health Data (2006) over the period 1960-2004, the share of health care expenditures in GDP among high income OECD countries rose by an average of 5\% per year. Only the rates for the U.S. (6.2\%) and France (5.7\%) exceeded this average. In 2002-2003, health care expenditures in OECD countries grew at an average of $4.8 \%$. The countries that experienced above average growth rates for health care expenditures, in descending order, are Luxembourg, Belgium, Hungary, Spain, the Czech Republic, Iceland, Korea, Turkey, Greece, and the U.S.

\section{FOCUS ON COST CONTAINMENT IN CANADA AND EUROPE}

The designs of health care systems in OECD countries with universal coverage vary in terms of how costcontainment is achieved. The system that is most likely to restrain health care expenditure growth through contractual cost savings and internal coordination and administrative simplicity is the public integrated system. An agency at the local or central government level controls funding and provision of care (Cutler 2002). Doctors are salaried and public hospitals are funded through a block grant. However, the absence of competition and choice under this system is more likely to compromise quality of care and patient satisfaction. Okunade et al. (2004) classified countries that combine public financing of health care with private delivery into those that employ the public reimbursement method (Australia, Belgium, France, Japan, Luxembourg, and Switzerland), and those that use the contract method (Denmark, Iceland, Ireland, the Netherlands). Under the public reimbursement method, providers are paid retrospectively (or after providing services to patients) by the public insurance fund, or by the patients who are later reimbursed in part or in full by the public insurance fund. The payments are considered more liberal, thus making cost control incentives under this system fairly weak. The contract system grants third party payers greater control over health expenditure budgets and their distribution than the reimbursement method. Public insurance agencies enter into a prospective agreement with primary care physicians who receive per diem caps for each registered patient. Hospitals are funded on a per diem or case mix basis.

Following the progress made by the U.S. in cost containment through managed care, Canada, the U.K. and other OECD countries in Europe adopted different measures beginning in the mid-1990s. Most of these measures were aimed at containing health care costs, but in some cases, increasing patient choice as well. The following summary of reform measures is based on an OECD-funded study by Docteur and Oxley (2003):

1. $\quad$ Cost-shifting (public to private) on the financing side

- $\quad$ increasing out-of-pocket payments through user fees, reimbursement caps, deductibles, or co-insurance

- $\quad$ reducing services covered by public insurance

- $\quad$ annual ceiling on national health care spending

- $\quad$ increasing co-pay for branded drugs by reimbursing patients only up to the cost of lowest priced, or generic drugs 
- $\quad$ allowing use of private complementary insurance to cover cost-share, and supplemental insurance to reduce waiting time or increase patient choice

2. $\quad$ Cost shifting on the delivery side

- $\quad$ contracting out ambulatory care to private practitioners to reduce demand for higher cost inpatient care

3. Increased use of ambulatory care gatekeepers and capitated payments

- $\quad$ paying primary care physicians (PCPs) a fixed amount per registered patient, depending on age or gender, as an incentive to find cost-effective treatments

- $\quad$ requiring PCP referral to see a specialist to reduce demand for more expensive specialty care

- $\quad$ coordinating PCP and specialist care to reduce cost and improve treatment outcomes.

4. Reimbursements using diagnosis-related group (DRG) payment schedules

- $\quad$ restraining providers from prescribing unnecessary services and over-pricing.

5. Increasing competition

- $\quad$ among insurers by allowing patients to shop for the most desirable cost-coverage mix

- $\quad$ among PCPs by allowing patients expanded choice or providers

- $\quad$ among hospitals for elective surgery to cut waiting times

- $\quad$ among ambulatory care providers by allowing autonomous purchasing authorities to enter into contracts with providers specifying volume caps and quality specifications.

In the case of prescription drugs, dental care and hospitalization, the average insured American probably has a lower out-of-pocket cost. According to a study by Scheil-Adlung (1998), a patient's share of drug costs varies widely across countries with universal coverage. Some were proportional (10-25\% in Greece, $20 \%$ in the Netherlands, 25-50\% in Denmark, and 35-65\% in France), and others were a fixed amount per prescription (\$5 in Austria and Italy, \$9-\$13 in Germany, \$8-\$48 in Australia). Quarterly deductibles equal to $\$ 57$ were used in the U.K. and \$211in Ireland. In most cases, exemptions or reductions were granted to those who had chronic illnesses, and to vulnerable groups (the poor, unemployed or elderly). The cost of dental services borne by patients were usually proportional (20\% in the U.K., 25\% in Belgium, 30\% in France, 25-50\% in Austria, 55-60\% in Denmark, $30-75 \%$ in Sweden, and $100 \%$ in Canada), but in the case of Australia a fixed deductible of $\$ 118$. Patient's co-pay for the costs of hospitalization and hospital supplies were used by Austria, Belgium, Germany, Ireland, and Sweden in the range of $\$ 9$ to $\$ 16$ per day. Austria capped the number of covered hospitalization to 28 days per year. In many countries, eye care and prescription glasses are not covered by public insurance.

Due to a longer experience with managed care, the U.S. is a step ahead of Canada and European countries in controlling the resulting cost-quality tradeoff. After two versions of a patient's bill of rights stalled in Congress in 2002, the Supreme Court upheld a patient's right to sue Health Management Organizations (HMOs) in state courts for alleged adverse effects on quality of care, and in some cases, death, arising from denial of coverage (Holt 2002).

\section{FOCUS ON EXPANDED ACCESS IN THE U.S.}

To put it simply, the uninsured in the U.S. consist of working adults who are not poor enough to qualify for Medicaid, too young for Medicare, and too old for SCHIP. According to a study of health initiatives by states funded by the R.W. Foundation (Academy Health, 2007) almost half of Hispanic and Native Americans, and about a fifth of non-elderly rural residents are uninsured. The number of uninsured Americans would have been much higher without Federal legislation that required states to increase the eligibility income cut-off for Medicaid from 25\% below FPL to 33\% above it between 1988 and 1993. Due to a consensus in Congress that access by low-income women to prenatal care would reduce the incidence of low birth weight and hence, infant mortality, the Federal 
government provided matching funds to states that extended Medicaid eligibility to pregnant women with incomes up to $185 \%$ FP (Fergusson 1999). As a result, World Bank development statistics show that between 1960 and 1998 the public share of national health expenditures in the U.S. increased five times, while the private share less than doubled. In 1960, public health expenditure was 1.2\% of GDP in the U.S., just about half of the OECD average (World Bank, 2007). This gap was closed in 1998, with U.S. public spending on health care rising to $6.1 \%$ of GDP, just above the OECD average was at $6 \%$.

We can expect the public share of total health expenditures in the U.S. to exceed the private share soon because of the following developments:

1) Addition of a prescription drug program to Medicare in 2006 (Hoadley et al. 2006),

2) Programs targeting universal coverage initiated between 2003 and 2006 by Maine, Vermont, and Massachusetts (Academy Health 2007), and

3) Ongoing efforts at expanding access to targeted groups (children, employees of small businesses, near poor working families) by at least 12 other states (McDonough et al. 2008, Academy Health, 2008).

Maine's Dirigo Health Reform Act of 2003 aims at universal coverage by 2009 through voluntary insurance purchase, targeting small businesses, the self-employed and individuals without access to employersponsored insurance and whose incomes are below $300 \%$ of the federal poverty level (FPL). Maine entered into an exclusive contract with the largest private insurance company to offer affordable plans with a sliding scale of discounted premiums, reductions in deductibles, and caps on out-of-pocket expenses depending on income.

Massachusetts Commonwealth Care was enacted in 2006, aiming at covering 95\% of the uninsured in three years by mandating individuals and employers with 11 or more employees to purchase one of three affordable benefit packages. State general revenues and federal matching grants for Medicaid will pay for free coverage to those with incomes below FPL, and subsidize employer and individual premiums. Beginning July 1, 2007, an eligible individual who does not purchase coverage will lose the personal exemption from income taxes that year, and pay a fine equal to half of the monthly cost of insurance for each month without coverage. For employers, the penalty is a share of health care cost in excess of $\$ 50,000$ that is billed to the state whenever uninsured full-time employees or their dependents access free care from hospitals and other providers.

Vermont's Catamount Health Plan was implemented in October 2007 and aims at universal coverage by 2010. The state offers a new insurance product with subsidies for individuals below 300\% FPL. Employers are mandated to provide coverage to their employees and penalties are assessed on those who do not. Funding comes from increased tobacco tax, federal matching grants for Medicaid, and subsidized premiums paid by enrollees. The state also offers chronic disease management for the Medicaid population.

Illinois, Pennsylvania, New York, Tennessee, Wisconsin, and Washington have begun working towards covering all children including those of families with incomes above the SCHIP eligibility level. States that are working towards expanded access for low-income adults and/or small businesses include Arkansas, Minnesota, New Mexico, Oklahoma, Oregon, Rhode Island, Tennessee, Utah, Montana, Pennsylvania, South Dakota, and West Virginia (Academy Health, 2008).

Three states unveiled plans for universal coverage in 2007: California, Pennsylvania and New Mexico (Academy Health 2008). However, Gov. Schwarzenegger's proposal failed to pass the California legislature last year. Under his "Prescription for Pennsylvania" plan, Gov. Rendell is continuing to develop a comprehensive single payer health care reform proposal that would achieve universal coverage, along with health systems improvements and rewards individuals for healthy behavior. Another proposal for universal coverage was unveiled in 2007 by New Mexico Gov. Richardson.

In the 2008 Presidential election, universal health coverage at the national level is on each primary candidate's agenda. While similar in containing goals for improving health care quality, containing costs, and subsidizing premiums for low income individuals and families, a major difference between the two is mandatory 
purchase under the Clinton Plan (Clinton 2007), and voluntary purchase under the Obama Plan (Obama 2007). The Clinton Plan is viewed to be superior because it addresses the adverse selection problem inherent in voluntary insurance, but Obama's ability to rally grassroots support to counteract countervailing forces from the drug industry and fiscal conservatives in Congress, probably gives him an edge in terms of actually getting a legislation passed. With the country still at war, and the economy's weakness contributing to the rising public debt, the passage of any universal health care legislation ultimately hinges on whether the Bush tax cut for the highest income Americans can be reversed as both Clinton and Obama intend to fund their plans with the resulting tax revenues. The more likely scenario is that the U.S. will continue treading on an incremental path to universal coverage with a mix of initiatives at the state and federal levels. One possibility will be the use of block grants from the federal government as in the post 1996 welfare program. This would make states 'laboratories' for different health plans, while at the same time equalizing their disparate revenue bases.

\section{CONCLUSION}

From the above discussion, it may be concluded that the health care systems of the U.S. and OECD countries with universal coverage are in the process of convergence, spurred by the challenging problem of providing high quality, but affordable, health care to all people. The design of health care systems in Canada and Europe now exhibit a trend towards the use of supplemental private insurance, reduced public coverage or increased patient's cost share, decentralization or reduced government control of health care delivery, the use of gatekeepers, DRG reimbursements, and other managed care practices that became widely used in the U.S. since the 1980s. At the same time, public expenditures for health care in the U.S. are expected to exceed private expenditures in the near future, mainly because of the Federal government's prescription drug program for the elderly, universal coverage programs implemented by three states, and many other state initiatives to expand access to health insurance through existing public programs as well as by subsidizing the purchase of coverage from private health insurers. It is likely that the U.S. will keep its predominantly private health insurance market, but it is not clear whether and when universal coverage at the national level through a federal mandate to purchase health insurance will become a reality.

\section{AUTHOR INFORMATION}

Adora Holstein, PhD., The Pennsylvania State University is an Associate Professor of Economics.

Patrick Litzinger, PhD., University of Pittsburgh is a Professor of Economics and Department Head.

\section{REFERENCES}

1. Academy Health. State of States: 2007. Compilation report prepared by the State Health Access Data Assistance Center, School of Public Health, University of Minnesota for Academy Health (National Program for State Coverage Initiatives of the Robert W. Johnson Foundation. http://www.statecoverage.net/pdf/stateofstates2007.pdf, January 2007.

2. State of States: 2008. Compilation Report prepared by the State Health Access Data Assistance Center, School of Public Health, University of Minnesota for Academy Health. http://www.statecoverage.net/pdf/stateofstates2008.pdf, January 2008.

3. Clinton, Hillary. American Health Choices Plan: Quality, Affordable Health Care for Every American. http://www.hillaryforpresident.com, 2007.

4. Cutler, David. Equality, Efficiency, and Market Fundamentals: The Dynamics of International Medical Care Reform," Journal of Economic Literature, Vol. 40, No. 3, pp. 881-906, September 2002.

5. Docteur, Elizabeth and Howard Oxley. "Health-Care Systems: Lessons from the Reform Experience," OECD Health Working Papers. DELSA/ELSA/WD/HEA(2003)9, OECD: Paris. www.oecd.org, 2003.

6. Embassy of France. The French Health Care System. Ministry for Health, Family and the Disabled. November 2007.

7. Fergusson, Christine and T. Leddy. The 'New Medicaid': An Incremental Path to National Health Care Reform. Family Planning Perspectives, Vol.31, No.3, pp. 148-149, 1999. 
8. Gruber, Jonathan. Covering the Uninsured in the U.S. NBER Working Paper 13758. http://www.nber.org/aginghealth/2008no1/w13758.html, 2008.

9. Hoadley, J., E. Hardgrave, J. Cubanski et al. An In-depth Examination of Formularies and Other Features of Medicare Drug Plans. Kaiser Family Foundation. April 2006.

10. Holt, Janet. Supreme Court Approves State Review of HMO Decisions; Congress Stalls. Trial, Vol. 38, No. 9, pp.12-16. September 2002.

11. McDonough, Miller et al. States Have Seized a Window of Fiscal Opportunity to Expand Access, but Whether Financing Will Be Sustainable May Depend on the Federal Government. Health Affairs, Vol. 27, No.2. http://content.healthaffairs.org/cgi/content/abstract/hlthaff.27.2.w105, 2008.

12. National Coalition on Health Care. Snapshots on Health Care. Washington D.C., http://www.nchc.org.

13. Obama, Barack. Plan for a Healthy America. http://www.barackobama.com/issues/healthcare/

14. Okunade, Albert, M. Karaku, and C. Okeke. Determinants of Health Expenditure Growth of the OECD Countries: Jackknife Resampling Plan Estimates. Health Care Management Science, Vol. 7, pp.173-184, 2004.

15. Organization for Economic Cooperation and Development. OECD Health Data. www.oecd.org, 2006.

16. Qureshi, Afsun. An "Internal Market" for the Canadian Health Care System: Introducing Market Rules to the Canadian Health Care System. Canada NewsWire. http://www.newswire.ca/releases/September1998/01/c0041.html.

17. Rodwin, Victor. The Health Care System under French National Health Insurance: Lessons for Health Care Reform in the U.S., American Journal of Public Health, Vol. 93, No.1, pp. 31-38, January 2003.

18. Scheil-Adlung, Xenia. Steering the Healthcare Ship: Effects of Market Incentives to Control Costs in Selected OECD Countries, International Social Security Review, Vol. 51, No.1, pp. 112-113, 1998.

19. Sparer, Michael. Medicaid and the Limits of State Health Reform. Philadelphia: Temple University Press, 1996.

20. $\quad$ World Bank. World Bank Development Statistics. Washington D.C.: World Bank, 2007. 